\title{
Where Trust Flourishes: Perceptions of Clinicians Who Trust Their Organizations and Are Trusted by Their Patients
}

\author{
Mark Linzer, MD \\ Hannab Neprash, PbD \\ Roger Brown, $\mathrm{PbD}$ \\ Eric Williams, $P b D$ \\ Crystal Audi \\ Sara Poplau \\ Kriti Prasad
}

Dbruv Kbullar, MD, MPP

*For the Healtby Work Place

Investigators

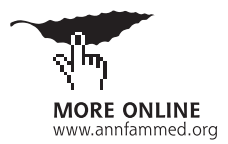

Conflicts of interest: M.L., S.P., and C.A. were supported for research and training in burnout prevention through Hennepin Healthcare and/or the Hennepin Healthcare Research Institute (HHRI) by the American Medical Association (M.L., S.P., C.A.) American College of Pbysicians (M.L., S.P.), and Institute for Healthcare Improvement (M.L., C.A.). M.L., S.P., and C.A. were supported in this project through Hennepin Healthcare and/or HHRI by the American Board of Internal Medicine Foundation. M.L. is also supported by the National Institutes of Health for work in shared decision making and burden of treatment and as a principal investigator on an Agency for Healthcare Research and Quality K12 Learning Health System training grant. He consults for Harvard University on a grant assessing work conditions and diagnostic accuracy. H.N., R.B., E.W., D. Kbullar, K.P., D. Kobuhorst, J.W., M.B. and L.H. were compensated for time on this project. L.H. receives book royalties, and M.B. bas stock options in Forward Health Group.

\section{CORRESPONDING AUTHOR}

Mark Linzer

Hennepin Healthcare (G5)

701 Park Ave

Minneapolis, MN 55415

mark.linzer@hcmed.org

\begin{abstract}
PURPOSE Trust is an essential component of health care. Clinicians need to trust organizational leaders to provide a safe and effective work environment, and patients need to trust their clinicians to deliver high-quality care while addressing their health care needs. We sought to determine perceived characteristics of clinics by clinicians who trust their organizations and whose patients have trust in them.
\end{abstract}

METHODS We used baseline data from the Healthy Work Place trial, a randomized trial of interventions to improve work life in 34 Midwest and East Coast primary care clinics, to identify clinic characteristics associated with high clinician and patient trust.

RESULTS The study included 165 clinicians with 1,132 patients. High trust by clinicians with patients who trusted them was found for $34 \%$ of 162 clinicians with sufficient data for modeling. High clinician-high patient trust occurred when clinicians perceived their organizational cultures to have (1) an emphasis on quality (odds ratio [OR] 4.95; 95\% Cl, 2.02-12.15; $P<.001)$, (2) an emphasis on communication and information (OR 3.21; $95 \% \mathrm{Cl}, 1.33-7.78 ; P=.01)$, (3) cohesiveness among clinicians (OR 2.29; $95 \% \mathrm{Cl}, 1.25-4.20 ; P=.008)$, and (4) values alignment between clinicians and leaders (OR 1.86; $95 \% \mathrm{Cl}, 1.23-2.81 ; P=.003)$.

CONCLUSIONS Addressing organizational culture might improve the trust of clinicians whose patients have high trust in them.

Ann Fam Med 2021;19:521-526. https://doi.org/10.1370/afm.2732.

\section{INTRODUCTION}

T rust in the medical profession has decreased since the 1960s among several demographic groups in the United States. ${ }^{1,2}$ A 1966 survey showed that $75 \%$ of Americans trusted medical professionals, decreasing to $33 \%$ by 2018 ; however, trust remains high within certain subgroups (eg, the elderly). ${ }^{2}$ Studies have shown that clinicians have variable trust in their organizations, ${ }^{3}$ and many patients express concerns that health systems will not safely care for them. ${ }^{4}$ Research on epidemics has shown that lack of trust decreases the likelihood of adherence to public health recommendations. ${ }^{1}$ Thus, it is important that factors be identified to assist health systems to better understand how to create the most trust within their environments.

A 2010 article in the Annals of Family Medicine studied patient trust in clinicians. ${ }^{5}$ In semistructured interviews, the authors assessed swift trust (in acute care settings) vs secure trust, which builds over time. Theirs is one of few theoretically based studies of trust in relationships and encounters. A recent issue of the Journal of the American Medical Association devoted several articles ${ }^{6-9}$ and an editorial ${ }^{10}$ to trust among patients and clinicians. These articles establish trust as a contemporary metric of concern. Yet, few address the clinical environments that foster trust by clinicians as well as by patients who trust them. The construct of trust, either a patient's 
trust in their clinician or a clinician's trust in their organization, revolves around caring, selflessness, benevolence, and a resonance of values. ${ }^{6-8,11}$

The Healthy Work Place (HWP) study, a randomized study of workplace interventions to improve clinician work conditions, ${ }^{12}$ surveyed clinicians and patients regarding trust. Figure 1 suggests that workplace characteristics and organizational culture are associated with a clinician's trust in the organization and patient trust in their clinician. We sought to answer the following question: what are the perceived characteristics of clinics by clinicians who trust their organizations and whose patients have trust in them?

\section{METHODS}

\section{Study Design}

The HWP study, described elsewhere, ${ }^{12,13}$ was a cluster randomized trial conducted at 34 Midwest and East Coast clinics. Primary care clinicians were eligible and enrolled for participation if they had been employed at a practice as a $\geq 0.5$ full-time equivalent for 1 year. All clinicians at identified clinics were approached for participation. Given initial power calculations, we recruited 3-7 clinicians per clinic and 6-8 patients with diabetes and/or hypertension from clinician panels. Clinics included academic, urban, suburban, and rural sites. Site-specific institutional review board approval was granted and informed consent obtained from participants.

The HWP study was based on the conceptual model of the Minimizing Error, Maximizing Outcome (MEMO) study, ${ }^{14}$ which linked clinician work conditions and organizational culture to clinician and patient outcomes (Figure 1). Kralewski and colleagues refer to Schein ${ }^{15}$ and others in defining organizational culture as a deep phenomenon including a set of assumptions that is transmitted to new team members as the organization's way of thinking and feeling. ${ }^{16}$ This definition,

Figure 1. Proposed conceptual model of work conditions, mediators, and final outcomes.

\begin{tabular}{|c|c|c|}
\hline Work conditions & $\begin{array}{l}\text { Clinician-patient } \\
\text { (intermediate) reactions }\end{array}$ & Final outcomes \\
\hline $\begin{array}{l}\text { Organizational } \\
\text { culture (eg quality, } \\
\text { values, cohesion, } \\
\text { communication, } \\
\text { information) }\end{array}$ & $\begin{array}{l}\text { Clinician trust } \\
\text { in organization } \\
\text { Patient trust } \\
\text { in clinician }\end{array}$ & $\begin{array}{l}\text { Clinician satisfaction } \\
\text { Burnout } \\
\text { Turnover } \\
\text { Patient safety } \\
\text { Adherence } \\
\text { Quality of care }\end{array}$ \\
\hline
\end{tabular}

articulated by Kralewski et $\mathrm{al}^{16}$ and based in part on the competing values framework of focus, structure, and outcomes, ${ }^{17}$ identifies 4 types of culture, 1 of which (participatory, or group culture) was associated with worker satisfaction. Group culture relates to teamwork, cohesion, participation, communication, morale, and mentoring; many of these constructs are embodied in the present study's culture scales.

Baseline data from the clinics included work conditions (eg, chaos, time pressure, work control, organizational culture), physician reactions (eg, trust, satisfaction, burnout), and patient perceptions (eg, trust, satisfaction). Most HWP metrics were developed and validated in the MEMO study. Organizational culture scales were adapted from a study by Kralewski et $\mathrm{al}^{18}$ of medical group practices (Supplemental

Table 1, https://www.AnnFamMed.org/lookup/suppl/ doi:10.1370/afm.2732/-/DC1). The present study combines baseline data from 17 intervention and 17 control clinics, with data collected from 2012 to 2014.

The primary outcome (Figure 1) was consonance of clinician and patient trust. Predictors in the model included organizational culture variables from Kralewski et $\mathrm{al}^{18}$ and the MEMO study. ${ }^{14}$ Clinician trust was scored from 1 (low) to 4 (high). The clinician trust measure included 5 questions on the following: sense of belonging, loyalty, responsibility to help clinicians with problems, safety culture (eg, reporting adverse events), and overall trust. Trust was measured as the mean response to these 5 uniform-polarity items; as in the MEMO study, ${ }^{14}$ high trust was defined as a score of $\geq 3$. The McDonald omega (internal consistency) value for the clinician trust metric was 0.83 (>0.7 was considered acceptable).

Patient trust was scored on the basis of an average of 4 questions drawn from a validated scale by Kao et $\mathrm{a}^{19}$ focusing on trust in clinicians (Supplemental Table 2, https://www.AnnFamMed.org/lookup/suppl/ doi:10.1370/afm.2732/-/DC1). Questions assessed trust in provider's judgement, ability to place patient health above money and health plan rules, and trust in general. The McDonald omega value for the patient trust metric was 0.96 . For the analysis, we dichotomized high-trust clinicians and high-trust patients vs low-trust clinicians and low-trust patients, and the distribution was split at high trust $=5$ vs low trust as scores $<5 .^{20}$ Patients with an average score of $5(55 \%)$ were 
considered as high trust. An analysis based on dichotomization was required because we needed to establish composites of high-trusting patients and clinicians and compare those with a group with low trust by patients and clinicians. This became our outcome measure, comparing predictors of high-high trust vs low-low trust groupings.

\section{Predictor Variables}

Organizational culture variables from Kralewski et al ${ }^{16}$ and the MEMO study ${ }^{14}$ included (1) an emphasis on quality, (2) values alignment between clinicians and leaders, (3) clinician cohesiveness, and (4) an emphasis on communication and information (Supplemental Table 1). These were scored in the same manner as the clinician trust variable, from 1 (low) to 4 (high). In prior work, these predictors (quality, values, cohesion, and communication) have been associated with clinician reactions (satisfaction and burnout) and with some aspects of quality of care and patient safety. ${ }^{14,21}$ We also assessed if work conditions, such as work control and chaos, were associated with high-high quadrant presence.

\section{Analysis}

To establish a patient-clinician linkage of trust, we aggregated patients to a single metric per clinician. If the proportion of high-trust patients under a clinician was $\geq 50 \%$, the patient group was linked to the clinician as a high-trust group. If the patient group was $<50 \%$ high trust, they were linked to the clinician as a lowtrust group. The high-high group had high-trust clinicians (average score $\geq 3$ of 4 on 5 trust items) and $>50 \%$ of their patients with high (perfect) trust on their trust scale. Dichotomization was justified, owing to skewed data (55\% with perfect [average score of 5] trust). We then created a $2 \times 2$ table of high and low clinician and patient trust and categorized clinicians and their associated patients into each of 4 quadrants including high-high (high clinician trust with high proportions of their patients trusting them), low-low (low clinician trust and low proportions of patients expressing trust in them), high-low (high clinician trust, low proportions of patients expressing trust), and low-high (low clinician trust, high proportions of patients expressing trust). We linked patients with clinicians, sorting linkages into quadrants, depending on trust ratings (Table 1). Multilevel logistic regression (with patient-clinician linkages nested within clinics) predicted the likelihood of being in the high-high vs the low-low quadrant. Models adjusted for clinician age, sex, role (physician vs advanced practice clinician), specialty (family practice vs general internal medicine), a binary measure of racial concordance of clinicians and patients, and number of patients clinicians cared for monthly. The

\section{Table 1. $2 \times 2$ Table of Clinician and Patient Trust Linkages}

\begin{tabular}{lcc}
\hline & $\begin{array}{c}\text { High Clinician } \\
\text { Trust, no. (\%) }\end{array}$ & $\begin{array}{c}\text { Low Clinician } \\
\text { Trust, no. (\%) }\end{array}$ \\
\hline High patient trust & $55(34.0)$ & $50(30.9)$ \\
Low patient trust & $21(13.0)$ & $36(22.2)$ \\
\hline Note: Clustered patients for 162 clinicians with sufficient data for modeling. \\
\hline
\end{tabular}

McKelvey-Zavoina pseudo $\mathrm{R}^{2}$ value $^{22}$ was calculated to assess the importance of culture variables leading to clinicians being in the high-high quadrant.

\section{RESULTS}

The study included 165 clinicians (105 in general internal medicine and 60 in family medicine) and 1,132 patients in 34 Midwest and East Coast clinics. Of 162 clinicians with sufficient data for modeling, there were 55 clinicians (34\%) and 358 patients with trust congruence in the high-high quadrant and 36 clinicians (22\%) and 245 patients with congruence in the low-low quadrant (Table 1). There was variability in patient and clinician trust scores, with patient trust scores (possible range 1-5) ranging from 4.2 to 4.9 (mean [SD]: 4.5 $[0.8]$ ), and clinician scores (possible range 1-4) ranging from 2.1 to 3.8 (mean [SD]: 2.8 [0.6]). Supplemental Table 3 (https://www.AnnFamMed.org/lookup/suppl/ doi:10.1370/afm.2732/-/DC1) shows demographic characteristics of clinicians and patients, with most clinicians being physicians (vs advanced practice clinicians), fairly evenly split between female and male, with approximately 12 years in practice. Patients had an average age of 64 years; $60 \%$ were female; one-quarter were of a racial or ethnic minoritized group including Black, Latinx, and Asian groups; and most rated their health fair to good. Table 2 shows culture variables associated with being in the high-clinician high-patient trust quadrant: emphasis on quality (odds ratio $[\mathrm{OR}]=4.95$; $P<.001)$, emphasis on communication and information $\left(\mathrm{OR}=3.21_{i} P=.01\right)$, cohesion among clinicians $(\mathrm{OR}=2.29 ; \mathrm{P}=.008)$, and values alignment between clinicians and leaders $(\mathrm{OR}=1.86 ; P=.003)$. Pseudo $\mathrm{R}^{2}$ values ranged from $49 \%$ to $70 \%$ of variance explained for being in the high-high quadrant. Additional logit model data are included in Supplemental Table 4 (https:// www.AnnFamMed.org/lookup/suppl/doi:10.1370/ afm.2732/-/DC1). Figure 2 shows rapid increases in likelihood of being in the high-high quadrant as culture variables increase by 1 point on the Likert scale. In the multivariate models, presence in the high-high quadrant was not significantly related to work conditions such as chaotic environment or work control. 


\section{Table 2. Multilevel Logistic Regression Models of Congruence of High and Low Trust in Clinicians and Patients}

\begin{tabular}{lcccc}
\hline Variable & $\begin{array}{c}\text { Values Alignment } \\
\text { Model }\end{array}$ & $\begin{array}{c}\text { Quality } \\
\text { Model }\end{array}$ & $\begin{array}{c}\text { Cohesion } \\
\text { Model }\end{array}$ & $\begin{array}{c}\text { Communication } \\
\text { Model }\end{array}$ \\
\hline OR $(95 \% \mathrm{Cl})$ & 1.86 & 4.95 & 2.29 & 3.21 \\
& $(1.23-2.81)$ & $(2.02-12.15)$ & $(1.25-4.20)$ & $(1.33-7.78)$ \\
McKelvey-Zavoina & 0.487 & 0.616 & 0.701 & 0.698 \\
$\quad$ pseudo R & & & & \\
$\begin{array}{l}\text { C-statistic } \\
\text { P }>|\mathrm{Z}|\end{array}$ & 0.804 & 0.866 & 0.854 & 0.827 \\
& .003 & .001 & .008 & .01 \\
\hline
\end{tabular}

$\mathrm{OR}=$ odds ratio

Note: Adjusted for the covariates of clinician age, clinician sex, physician vs advanced practice clinician, specialty (family medicine vs internal medicine), average clinician monthly patient load, and racial concordance between clinician and patients. Details provided in Supplemental Tables 3 and 4. The McKelvey-Zavoina pseudo $\mathrm{R}^{2}$ approximates percent of variance explained in being in high-high category by organizational culture characteristic.22

\section{DISCUSSION}

In the present analysis of data from the Healthy Work Place study, we identified the following 4 culture variables within organizations that are more likely to be associated with high trust among clinicians whose patients expressed trust in them: emphasis on quality (OR 4.95), emphasis on communication and information (OR 3.21), clinician cohesion (OR 2.29), and values alignment between clinicians and leaders (OR 1.86). Improving organizational culture might thus be useful to establish trust among clinicians and patients with trust in them, with organizational culture accommodating elements of the therapeutic relationship ${ }^{23,24}$ and partnership models of care. ${ }^{25}$

Whereas prior work has examined factors associated with clinician trust ${ }^{13}$ and patient trust ${ }_{1}^{26}$ the present study identified culture variables perceived by clinicians with patients who trust them. We found culture characteristics, such as values alignment and emphases on quality and communication, and for which clinicians and organization leaders are key stakeholders, to be significantly associated with increased trust among clinicians who are trusted by patients. The implications of these findings require further study looking separately at clinician and patient trust.

Many current strategies to improve trust focus on adjusting financial incentives. Our present results suggest that aligning values and focusing on quality might offer other incentives to increase trust in clinicians with patients who find them trustworthy. We cannot determine whether clinicians within quality-emphasis organizations are less productive. There could be important downstream benefits, such as less clinician turnover, more healthy patient behaviors, and greater rates of medication adherence, resulting from high physician and patient trust. ${ }^{27}$

Recently, Zulman and colleagues ${ }^{28}$ looked at how physicians might engender trust among patients. The authors determined the following 5 mechanisms to improve physicianpatient connections: (1) prepare with intention, (2) listen intently, (3) agree on what matters, (4) connect with the patient's story, and (5) explore emotional cues. Some of these have been shown to improve trust, whereas others, such as approval, empathy, reassurance, and partnership, are associated with improved patient outcomes. We speculate that the 4 culture variables that we identified that matter to clinicians might facilitate (or if absent, impede) these meaningfulness-building activities by creating a more welcoming climate for deeper connections with patients by slowing down to emphasize quality care, aligning values on the patient mattering most, improving cohesion for clinician support, and emphasizing communication to allow greater listening by clinicians and storytelling by patients.

A study of Swedish health care workers also links trust and practice cohesion. ${ }^{29}$ In that study, feelings of camaraderie, as well as the joy of working together professionally, contributed to the success that teams felt during challenging situations, which might have then led to organizational trust. Our present study provides parsimonious and valid measures to quantify success in 4 culture domains, ${ }^{30}$ as well as for measuring clinician and patient trust (Supplemental Table 2). Organizations could consider routinely assessing such measures in efforts to improve clinician and patient trust.

The present study has limitations including the narrow focus on clinicians who trust their organizations and patients who trust them. By focusing on the highhigh quadrant, we did not include information from discordant quadrants (eg, high clinician trust and low patient trust). In addition, congruence of high clinician and patient trust might represent an unmeasured confounder such as organizational quality. Furthermore, there was heterogeneity of trust scores in patients and clinicians. The generalizability of findings beyond primary care clinics in the Midwest and East Coast is uncertain. Whereas the enrolled numbers of clinicians (165) did not reach sample size goals (238), this is mainly of importance in the randomized trial portion not reported here. Owing to the small number of clinicians per clinic (5), other variables associated with high trust might not have been identified. Regarding strengths, HWP clinics included a mix of academic, 
Figure 2. Organizational culture variables and probability of clinicians having high trust in their organization and patients having high trust in their clinician (high-high).

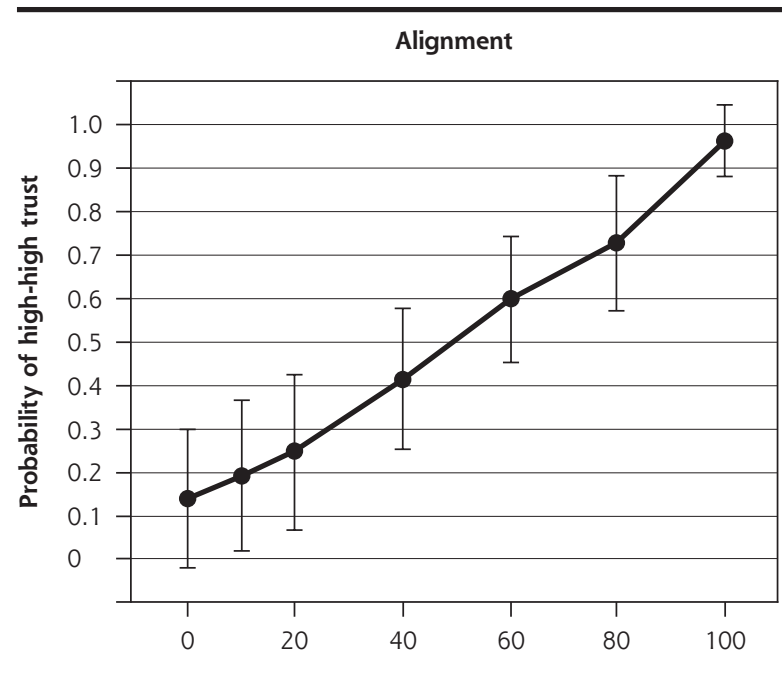

Alignment percentile

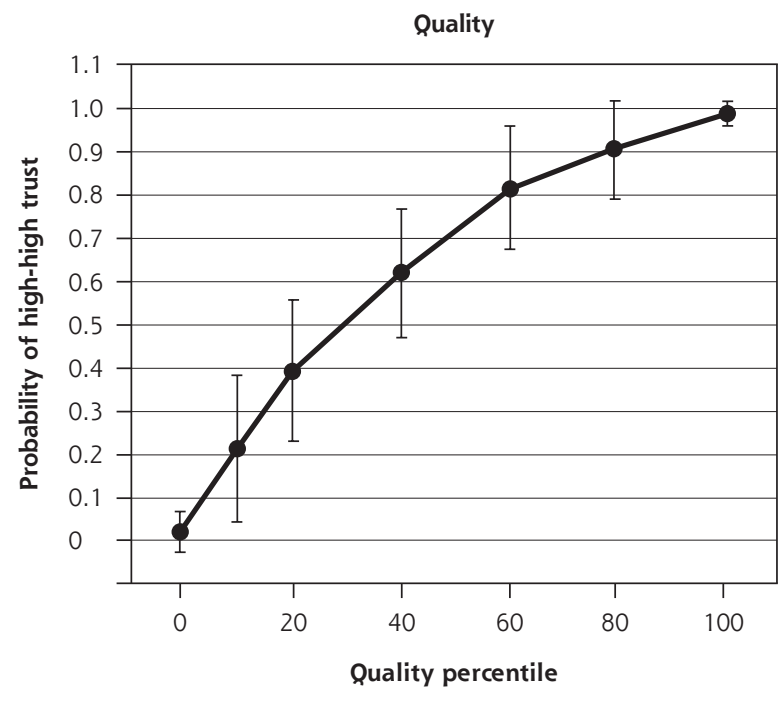

Cohesiveness

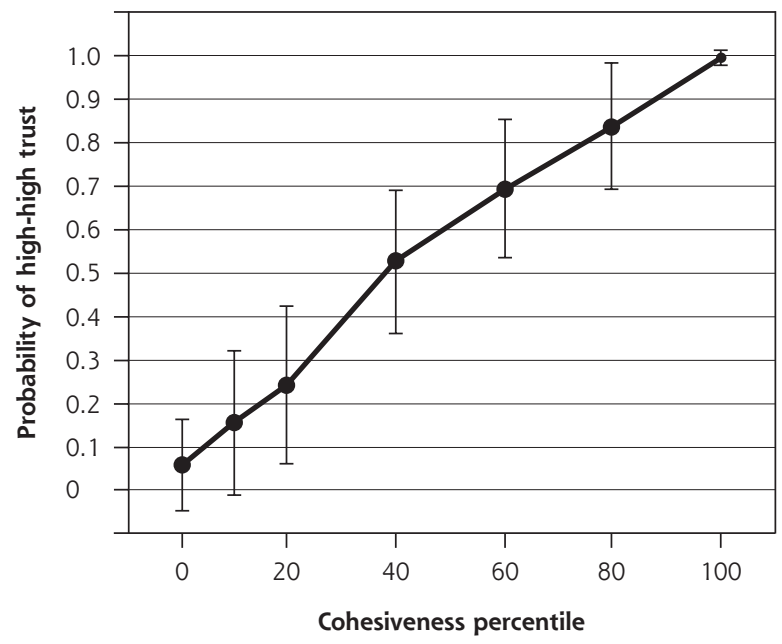

Communication

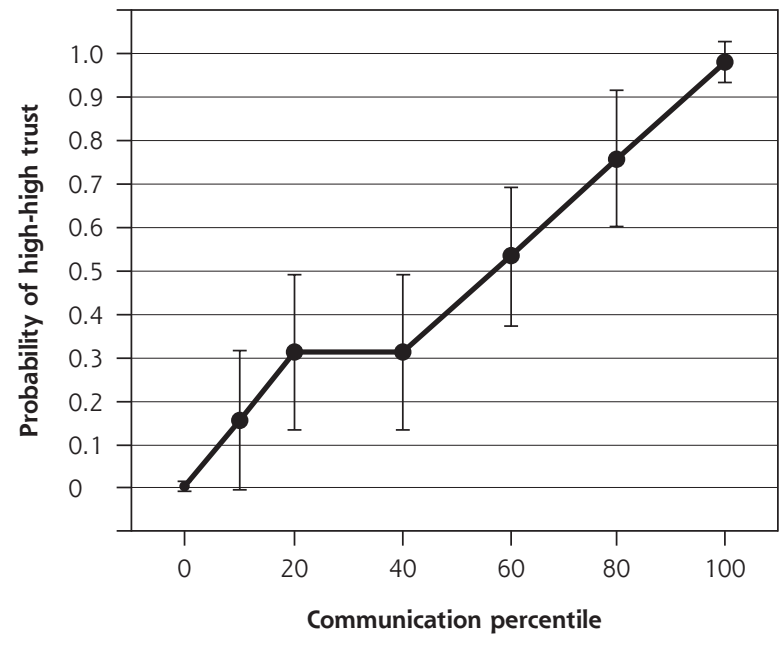

Note: Increase in probability of being in high-high quadrant for each percentile increase in organizational culture items.

inner city, rural, and suburban sites, the study was based on a strong conceptual model, and work-life measures are for the most part well validated.

To read or post commentaries in response to this article, go to https://www. AnnFamMed.org/content/19/6/521/tab-e-letters.

Key words: trust; organizational culture; quality of health care; communication

Submitted July 29, 2020; submitted, revised, April 1, 2021; accepted April 13, 2021.

Funding support: American Board of Internal Medicine Foundation grant, and Agency for Healthcare Research and Quality grant \#5R18-HS018160-03.

Author affiliations: Hennepin Healthcare Research Institute, Hennepin Healthcare, Minneapolis, MN (M.L., C.A., S.P.); University of Minnesota,
Minneapolis, MN (H.N., K.P.); University of Wisconsin School of Nursing, Madison, WI (R.B.); University of Alabama, Tuscaloosa, AL (E.W.); Weill Cornell Medical College, New York, NY (D.K.).

*Healthy Work Place Investigators include those listed above and Steven Yale, MD, University of Central Florida College of Medicine, Orlando, FL; Anita Varkey, MD, Loyola University Stritch School of Medicine, Maywood, IL; Ellie Grossman, MD, Cambridge Health Alliance, Cambridge, MA; Lanis Hicks, PhD, University of Missouri Health Management and Informatics, Columbia, MO; Michael Barbouche, MA, Forward Health Group, Madison, WI; Jill Wallock, Loyola University Stritch School of Medicine, Maywood, IL; and Diane Kohnhorst, Marshfield Clinic Research Institute, Marshfield, WI.

Author contributions: M.L. was principal investigator for the Healthy Work Place (HWP) trial and oversaw that and the present project. He also contributed to data interpretation and analysis and writing; R.B. was statistician for the project and performed the analyses; S.P. was 
Project Manager for the HWP trial and contributed to the paper; D. Khullar codirected the present project and contributed to data analysis and writing; E.W. contributed to study design and writing; C.A. was Project Manager for the paper and contributed to writing; K.P. contributed to organizing and writing; H.N. contributed to study design, analysis, and writing; S.Y., A.V., and E.G. were Site Directors for the HWP trial and contributed to data collection and analysis of the early HWP data; D. Kohnhorst and J.W. contributed to data collection, M.B. to study design, and L.H. to data interpretation. M.L. and R.B. had access to study data and take responsibility for integrity and accuracy of data analyses.

Supplemental materials: Available at https://www.AnnFamMed. org/lookup/suppl/doi:10.1370/afm.2732/-/DC1.

\section{References}

1. Khullar D. Do you trust the medical profession? The New York Times. January 25, 2018. Accessed Oct 2, 2021. https://www.nytimes. com/2018/01/23/upshot/do-you-trust-the-medical-profession.html

2. Blendon RJ, Benson JM, Hero JO. Public trust in physician--U.S. medicine in international perspective. N Engl J Med. 2014;371(17): 1570-1572.

3. Sandy LG, Pham HH, Levine S. Building trust between physicians, hospitals, and payers: a renewed opportunity for transforming US health care. JAMA. 2019;321(10):933-934.

4. Lee TH, McGlynn EA, Safran DG. A framework for increasing trust between patients and the organizations that care for them. JAMA. 2019;321(6):539-540.

5. Tarrant C, Dixon-Woods M, Colman AM, Stokes T. Continuity and trust in primary care: a qualitative study informed by game theory. Ann Fam Med. 2010;8(5):440-446.

6. Khullar D, Darien G, Ness DL. Patient consumerism, healing relationships, and rebuilding trust in health care. JAMA. 2020;324(23): 2359-2360.

7. Gupta R, Binder L, Moriates C. Rebuilding trust and relationships in medical centers: a focus on health care affordability. JAMA. 2020; 324(23):2361-2362.

8. Jain $\mathrm{SH}$, Lucey $\mathrm{C}$, Crosson FJ. The enduring importance of trust in the leadership of health care organizations. JAMA. 2020;324(23): 2363-2364.

9. Wheelock A, Bechtel C, Leff B. Human-centered design and trust in medicine. JAMA. 2020;324(23):2369-2370.

10. Baker DW. Trust in health care in the time of COVID-19. JAMA. 2020;324(23):2373-2375.

11. Chen W, Feng $Y$, Fang J, et al. Effect of trust in primary care physicians on patient satisfaction: a cross-sectional study among patients with hypertension in rural China. BMC Fam Pract. 2020;21(1):196.

12. Linzer M, Poplau S, Grossman E, et al. A cluster randomized trial of interventions to improve work conditions and clinician burnout in primary care: results from the Healthy Work Place (HWP) study. J Gen Intern Med. 2015;30(8):1105-1111.

13. Linzer M, Poplau S, Prasad K, et al; Healthy Work Place Investigators. Characteristics of health care organizations associated with clinician trust: results from the Healthy Work Place study. JAMA Netw Open. 2019;2(6):e196201.
14. Linzer M, Manwell LB, Williams ES, et al; MEMO (Minimizing Error, Maximizing Outcome) Investigators. Working conditions in primary care: physician reactions and care quality. Ann Intern Med. 2009; 151(1):28-36.

15. Schein $\mathrm{EH}$. What you need to know about organizational culture. Train Dev J. 1986;40(1):30-33.

16. Kralewski JE, Kaissi A, Dowd BE. Culture as a management tool for medical groups. Published Sep 2, 2008. Accessed Feb 16, 2021. https://www. physicianleaders.org/news/ culture-management-tool-medical-groups

17. Quinn RE, Rohrbaugh J. A spatial model of effectiveness criteria: towards a competing values approach to organizational analysis. Manage Sci. 1983:29(3):363-377.

18. Kralewski J, Dowd BE, Kaissi A, Curoe A, Rockwood T. Measuring the culture of medical group practices. Health Care Manage Rev. 2005;30(3):184-193.

19. Kao AC, Green DC, Davis NA, Koplan JP, Cleary PD. Patients' trust in their physicians: effects of choice, continuity, and payment method. J Gen Intern Med. 1998;13(10):681-686.

20. MacCallum RC, Zhang S, Preacher KJ, Rucker DD. On the practice of dichotomization of quantitative variables. Psychol Methods. 2002; 7(1):19-40.

21. Perez HR, Beyrouty M, Bennett $K$, et al. Chaos in the clinic: characteristics and consequences of practices perceived as chaotic. J Healthe Qual. 2017;39(1):43-53.

22. McKelvey RD, Zavoina W. A statistical model for the analysis of ordinal level dependent variables. J Math Sociol. 1975;4(1):103-120.

23. Chochinov HM, McClement SE, Hack TF, et al. Health care provider communication: an empirical model of therapeutic effectiveness. Cancer. 2013;119(9):1706-1713.

24. Pellegrini CA. Trust: the keystone of the patient-physician relationship. J Am Coll Surg. 2017;224(2):95-102.

25. Grob R, Darien G, Meyers D. Why physicians should trust in patients. JAMA. 2019;321(14):1347-1348.

26. Thom DH, Campbell B. Patient-physician trust: an exploratory study. J Fam Pract. 1997;44(2):169-176.

27. Schoenthaler A, Montague E, Baier Manwell L, Brown R, Schwartz MD, Linzer M. Patient-physician racial/ethnic concordance and blood pressure control: the role of trust and medication adherence. Ethn Health. 2014;19(5):565-578.

28. Zulman DM, Haverfield MC, Shaw JG, et al. Practices to foster physician presence and connection with patients in the clinical encounter. JAMA. 2020;323(1):70-81.

29. Öhman A, Keisu BI, Enberg B. Team social cohesion, professionalism, and patient-centeredness: gendered care work, with special reference to elderly care - a mixed methods study. BMC Health Serv Res. 2017;17(1):381.

30. Linzer M, Baier Manwell L, Mundt M, et al. Organizational climate, stress, and error in primary care: the MEMO study. In: Henriksen K, Battles JB, Marks ES, Lewin DI, eds. Advances in Patient Safety: From Research to Implementation. Volume 1: Research Findings. Agency for Healthcare Research and Quality; 2005. Accessed Jul 14, 2020. https://www.ncbi.nlm.nih.gov/books/NBK20448/ 